\title{
Legal incentives to diversify agricultural production in Uganda (suggesting lessons for the EAC)
}

\author{
by John OSAPIRI*
}

Research Presentation at the Online Leaders for Justice Workshop November 2020, organized by Konrad Adenauer Shiftung, Nairobi.

November 2020.

\section{PREFACE:}

This paper describes the East African Community regional integration cooperation in agriculture in a nutshell and gives a brief overview of the status of the agriculture sector in Uganda. The author furthermore considers in detail the relevant legal framework for the Agricultural sector in Uganda and finally discusses the legal incentives offered by the government to the agriculture in Uganda, from which the East African Partner States can draw lessons.

\section{A. INTRODUCTION.}

Uganda is a member of the East African Community (EAC) having signed the Treaty Establishing the East African Community. ${ }^{1}$ The EAC is a regional intergovernmental organisation comprising of six partner states namely Uganda, Kenya, United Republic of Tanzania, Rwanda, Burundi and South Sudan, with its headquarters in Arusha Tanzania ${ }^{2}$

The work of the EAC is guided by its Treaty which established the Community. It was signed on 30 November 1999 and entered into force on 7 July 2000 following its ratification by the original three Partner States - Kenya, Tanzania and Uganda. The Republic of Rwanda and the Republic of Burundi acceded to the EAC Treaty on 18 June 2007 and became full Members of the Community with effect from 1 July 2007. The Republic of South

* The Author is the Chief Executive Officer of Uganda Christian Lawyers' Fraternity, and a Consultant on Regional Integration and cross border trade and investment. He is a Co-founder of the Center for Regional Integration in Uganda, a regional integration think tank. He holds a Masters of Laws with a Focus on Regional Integration from the University Dar es Salaam. He has extensively received training internationally at the University of Bayreuth Germany focusing on European Union Integration and the Germany Federal Systems of governance. His areas of interest are Regional integration law, Trade and Investment law, Commercial and Corporate practice and NGO Management.

1 Article 3 (1), Treaty Establishing the East African Community.

2 The East African Community, 'EAC at a glance, 2020.' Accessed on www.eac.int accessed on $1^{\text {st }}$ November, 2020. 
Sudan acceded to the Treaty on 15 April 2016 and become a full Member on 15 August 2016.

The EAC is home to approximately 177 million citizens, of which over $22 \%$ is urban population. The EAC has a land area of 2.5 million square kilometers and a combined Gross Domestic Product of US\$ 193 billion. ${ }^{3}$ The EAC is considered the fastest integrating regional bloc on the African Continent, witnessed by its milestones in the shortest time which includes the implementation of the Customs Union and the Common Market.

As one of the fastest growing regional economic blocs in the world, the EAC is widening and deepening co-operation among the Partner States in various key spheres for their mutual benefit. These spheres include political, economic and social.

At the moment, the regional integration process is in full swing as reflected by the encouraging progress of the East African Customs Union, the establishment of the Common Market in 2010 and the implementation of the East African Monetary Union Protocol which will be operationalized in 2024 and then after the Political Federation.

One of the areas of mutual cooperation within the EAC under the Common Market Protocol is cooperation in Agricultural and food security. ${ }^{4}$ The Partner States are to undertake to sustainably develop and promote agriculture with regards to crops, livestock, fish, forestry and their productions. The Partner States are to also ensure food security in the community through access to quality and sufficient food. ${ }^{5}$ Therefore in the bid to promote agricultural productivity, the other EAC states can draw lessons from Uganda's legal incentives to spur Agriculture.

\section{B. AGRICULTURE IN UGANDA.}

Agriculture remains the major source of livelihood in Uganda. The bigger proportion of the working population is engaged in agriculture, forestry and fishing. Those engaged in such economic activities comprise for at least $65 \%$ of the population. Among the females in the working population, $70 \%$ are engaged in agriculture compared to $58 \%$ of the males. ${ }^{6}$

Furthermore, $38 \%$ of persons in employment are in paid employment with a higher proportion of males accounting for $46 \%$ compared to females at $28 \%$. The Agricultural sector accounted for the largest share of employment at $36 \%{ }^{7}$

The agriculture sector had a total contribution to GDP at current prices of 24.9 percent in the 2016/17 financial year, compared to 23.7 percent in 2015/16 financial year. The food

3 EAC Statistics for 2019, see also the EAC Trade Report 2018 http://repository.eac.int/bitstream/han dle $/ 11671 / 2057 /$ EAC\%20Trade $\% 20$ Report $\% 202018$.pdf? sequence=1\&isAllowed=y accessed on $2^{\text {nd }}$ November 2020.

4 Article 45 of the East African Community Common Market Protocol.

5 Ibid, Article 45 (1 and 2).

6 Uganda National Household Survey (UNHS) 2016/17

7 Ibid. 
crop sub sector registered the highest contribution within the agricultural sector of 13.6 percent in 2016/17 financial year, an increase from 12.1 percent in 2015/16 financial year. ${ }^{8}$

From the above statistical data, agriculture forms the back bone of Uganda's economy. It is therefore expedient that incentives be adopted to spur production. This paper therefore analyses the agricultural policies in Uganda to determine the incentives presented by the Government of Uganda to the Agricultural Sector for the benefit of other EAC Countries.

Uganda should set an example to other East African Community countries since as one of the 55 member states of the African Union, Uganda has steadily picked the pace in agricultural development and was highlighted as one of the 20 leading countries in delivery on development targets of the Comprehensive Africa Agriculture Development Programme (CAADP). ${ }^{9}$

\section{Overview of the Legal Framework of Agriculture in Uganda.}

There are pertinent issues in the sector that need to be regulated for the sector to be effectively managed. The regulation in the agricultural sector starts with land management and thereafter deals with the unique legal issues associated with the sector. These include regulation of land for agriculture purposes, soil governance, livestock management, crop production and management, regulation of water for agriculture, pesticides control, fertilizer management, regulation of investment in the agriculture sector and taxation. Without the legal and institutional arrangements that regulate the agriculture sector, it is difficult to promote incentives in the sector ${ }^{10}$

The Constitution of the Republic of Uganda, 1995: The Constitution provides for adoption of measures required to protect the environment and natural resources and creates an obligation for the State to stimulate agricultural development by adopting appropriate policies and the enactment of enabling legislation. ${ }^{11}$

The National Development Plan (NDP) (Republic of Uganda, 2010 also stands out to support agricultural production as one of the tools that will contribute to national development.

The National Agricultural Research Act, 2005: The overall goal of the National Agricultural Research Act (2005, No. 9) is to address challenges presented in the Plan for

8 Ibid

9 The Ministry of Agriculture, Animal Husbandry and Fisheries, 'Agricultural Sector Potential in Uganda, 2020. www. Agriculture.go.ug accessed on $30^{\text {th }}$ October, 2020. (CAADP) is Africa's policy framework for agricultural transformation, wealth creation, food security and nutrition, economic growth and prosperity for all.

10 Emmanuel Kazimbazi, 'Legal and Regulatory Framework for the Agriculture Sector in Uganda.' in International Yearbook of Soil Law and Policy book series (IYSLP). https://link.springer.com/c hapter/10.1007/978-3-030-36004-7_4 accessed on 2nd November 2020.

11 National Objective XIII of the 1995 Constitution of Uganda mandates government to Provides for Protection of Natural resources, and Article 245 of the 1995 Constitution of Uganda was legislated to guarantees the protection and preservation of the environment. 
Modernization of Agriculture (PMA) and the National Agricultural Research Policy (NARP). The Development Strategy and Investment Plan (DSIP) of Uganda supports adoption of various relevant technologies that can contribute to enhancing agricultural production, productivity, and value addition. The Development Strategy and Investment Plan (DSIP) of Uganda further provides for "improving capacity for regulation and enforcement especially in safety standards and quality assurance across crops, livestock and fisheries".

The Agricultural Chemicals (Control) Act, 2006: It is noteworthy to compare this Act to the proposed Biotechnology and Biosafety law. The Agricultural Chemicals Act provides for control and regulation of the manufacture, storage, distribution and trade in, use, importation and exportation of, agricultural chemicals. The Act establishes an Agricultural Chemical Control Board that ensures chemicals are duly registered and are used in accordance with the regulations provided under the Act. The powers of this board can be equated to that of the National Biosafety Committee, a technical committee at the Uganda National Council for Science and Technology that is responsible for biosafety. Agricultural chemicals when well regulated and used properly can result in significant gains for the farmers.

National Environment Act: The National Environment Act (Cap 153) provides for the principles of environmental management and enforces the constitutional call for a right to a clean and healthy environment. It does this by establishing administrative structures, with the National Environmental Management Authority (NEMA) as the apex Government agency for environmental management in Uganda. The Act charges NEMA with the responsibility of conducting environmental impact assessment (EIA) before any project likely to have an impact on the environment is undertaken. This law mentions aspects of agriculture in environmental management. Therefore, environmental conservation is key for agricultural production, since it is a source of rainfall.

The Plant Protection and Health Act, 2015: This Act provides for the prevention of the introduction and spread, and eradication of pests and diseases destructive to plants. The Act regulates the introduction of exotic plants and microorganisms. The commissioner for agriculture works with inspectors to control the importation and exportation of articles that can result in the spread of diseases or pests. The Act therefore guarantees food production as it seeks to eradicate pests that destroy crops and also prevents the introduction of exotic plants not approved by government, which seeks to protect the indigenous species.

The Food and Drug Act, Cap 278: This Act provides for offences connected with the preparation and sale of injurious foods and adulterated drugs. The Act also provides for standards for foods and drugs. However, the legislation does not address aspects of packaging, crop planning and documentation in farm management. Descriptive documentation of a farmer's data is essential for identifying, finding, accessing, and using the data in the future. Documentation is not only important for other researchers who may use the data, but also for the farmer. Data documentation helps in remembering the details of your project 
that may otherwise be forgotten with time. Data documentation is easier and much less time consuming if it is performed at each stage of the process instead of waiting until the end. ${ }^{12}$

The National Agricultural Research Act, 2005: The overall goal of this Act is to address challenges presented in the Plan for Modernization of Agriculture (PMA) and the National Agricultural Research Policy (NARP). This Act provides for the development of an agricultural research system to improve research service delivery in the country. Section 5 establishes the National Agricultural Research Organization (NARO) whose major function is to provide guidance and coordinate all agricultural research activities in Uganda. The Act therefore is a bedrock for research in agriculture development especially with regard to crop yields with high productivity rates. Uganda has therefore made a commendable process in developing high yielding crop species.

The Public Health Act (Cap 281): It was enacted into law in 1935. It provides for the preservation of public health. It covers standards for sanitation, vaccination and prevention of infectious diseases. The Act also provides for administrative structures for enforcing the standards and requirements provided therein. This act is relevant to the agricultural sector because farmers are constrained to produce food or yields that are meant to meet public health standards but also preserve life.

The Uganda Food and Nutrition Policy (2003): In recognition of the vicious cycle between poverty and malnutrition, a multi-sectoral effort was undertaken to provide a framework for addressing food and nutrition issues in the country. The result was the Uganda Food and Nutrition Policy [UFNP] (Republic of Uganda, 2003) developed within the context of the overall national development policy objective of eradicating poverty as spelt out in the Poverty Reduction Strategy of Uganda (PEAP). The major policy focus is food security, improved nutrition and increased incomes. Government of Uganda, in 1987, established the National Food and Nutrition Council (NFNC) to coordinate activities relating to food security and nutrition. UFNP provided for establishment of the UFNC as a coordinating body for the multi-sectoral implementation of the UFNP. A more recent and complementary document for this policy is the National Food and Nutrition Strategy (Republic of Uganda, 2005) which was updated in 2010 as guided by the NDP. The NDP obliges government to directly invest in the Agricultural sector for sustainability.

The Coffee Act 2020: This Act was passed on $5^{\text {th }}$ August, 2020. The Act established the Coffee Marketing Authority to regulate and oversee the Coffee sector. The act also covers on farm coffee activities, off farm activities and processing of coffee. The Act also seeks to guarantee coffee production by requiring coffee farmers to register, register the size of their land on which plantations are done, register coffee buyers, sellers and nursery bed operators.

The Sugar (Control) Act, Cap. 34: This act intends to regulate issuance of sugar export licenses, impose restrictions on the sugar that should be held in stock and provides for

12 Precision Agriculture, 'Benefits of Documenting Data in Farm Management,' https://precisionagri cultu.re/benefits-of-documenting-data-in-farm-management/ accessed on $2^{\text {nd }}$ November, 2020. 
fixing of the amount of sugar that should be exported. The Act puts a quota on the amount of sugar to be exported with exception of the East African Countries. The Minister of trade is vested with the powers to determine the quota of the sugar that is to be exported to other Countries. ${ }^{13}$ The Minister is also entitled to receive financial statements with respect to the production of sugar from manufacturers. ${ }^{14}$

The above Act is supplemented by the Sugar Cess Act Cap. 343, which imposes a cess to be paid by every manufacturer of a sugar producer. ${ }^{15}$ The act provides that the funds obtained from the Sugar Cess shall be allocated to the Sugar Cess Fund and shall be used as the Minister shall direct. ${ }^{16}$

The above are some of the laws related to Agriculture, the EAC countries could borrow from the so many Ugandan laws, in case a specific Partner state does not have the said law.

\section{THE LEGAL INCENTIVES TO AGRICULTURE IN UGANDA}

Some Ugandan authors have taken the initiative to discuss some of the legal incentives to the Agricultural sector in Uganda; ${ }^{17}$ these incentives include;

\section{Access to Finance:}

The Agricultural sector would not operate without producers borrowing money to acquire production land, production inputs or animals. The Legal system provides a mechanism for lending of money, securing repayment of loans through mortgages on land and security interests of the borrower. The Loans Act, Cap. 236 makes provisions for raising loans to finance development schemes, projects and other purposes connected therein. The Financial Institutions Act, 2004 also revised and consolidated laws relating to financial institutions, to provide for regulations, control and discipline of financial institutions by the Central Bank: and to provide for other related matters.

\section{Land transfers and acquisition}

Farmers must have access to land to be able to produce. The Ugandan system of land acquisition provides a mechanism for the acquisition, ownership and transfer of land interests.

13 Section 2, Sugar (Control) Act.

14 Ibid, Section 5.

15 Section 1, Sugar Cess Act.

16 Ibid, Section 3, Sugar Cess Act.

17 Aziz Kitaka, Agriculture and the Law in Uganda (with cases and other relevant materials) in Academia, https:/www.academia.edu/39963734/Agriculture_and_the_Law_in_Uganda_With_cases_a nd_other_relevant_materials_accessed on 6th November, 2020. 
The Constitution provides that any person has a right to own land either individually or in association with others. ${ }^{18}$

The Constitution further provides that the government may under the laws made by Parliament and policies made from time to time regulate the use of land. ${ }^{19}$ This led to the enactment of several laws that preserve rights in lands which are either legal or equitable rights. Additionally, the Constitution provides that land shall be owned in accordance with tenures established including Customary, Freehold, Mailo and Leasehold. ${ }^{20}$ These provisions guarantee the ownership of land by farmers, which facilitates production.

For a farmer to confidently carry out production or farming activities, he or she must be the rightful owner of the land where such agricultural activities are being carried out or otherwise their interests may be challenged on the land or they may be forcefully evicted from that land if the matter is brought to court.

\section{Farmland Tenancy;}

Some farmers in Uganda grow crops and rear crops on land owned by other people. The development of the landlord tenant laws which provide for temporary use of land by another, with the assurances of being paid rent, makes the extensive use of leases, hire of land and rent possible. This is possible because the Land Act guarantees the payment of rent to the owner of registered land. ${ }^{21}$

\section{Transfer of farm operations}

Most farms are essentially owned as a form of small businesses. They have a natural life span relating to the life and interests of owners. The legal system provides a process to transfer farm operations as a continuing business, either through intergenerational transfers to heirs by will or trusts or through the sale of farm assets and the farm itself.

\section{$V$. The buying and selling of necessary farm inputs.}

Access to agricultural capital incentives has increased of recent as purchased seeds, fertilizers, chemicals and equipment in the production have been made available. These have become significant factors that facilitate production. Marketing this input to the Agricultural sector and assuring their effectiveness and safety is facilitated by existing laws.

The Sale of Goods and Supply of Services Act, 2017 provides for the formulation, effect, obligations and performance of contracts for the sale of goods and supply of services. Section of 2 of the Act provides for sale and agreement to sale goods by which the seller

18 Article 26 (1), 1995 Constitution of the Republic of Uganda.

19 Ibid, Article 242.

20 Ibid, Article 237 (3).

21 Section 35, Land Act Cap. 227 as amended. 
transfers or agrees to transfer property in goods for a consideration. The Contracts Act 2010 codifies the laws relating to Contracts in Uganda. Specifically, Section 10 of the Contracts Act provides that contracts shall be made orally or in writing. Contracts regarding Agricultural outputs are therefore covered under this section.

\section{Facilitating the formation of businesses;}

Many farms and farm businesses are organized as partnerships or corporations. Even the subsistence farmers also end up starting up small businesses (roadside businesses). It is easy to form business vehicles like Companies and Partnerships that facilitate Agriculture. The ability to utilize the various legal entities to form and operate agricultural related business gives the sector access to finance, limited liability and business operational benefits provided by flexibility in organizational structures. For example The Trade Licensing Act 1969 provides for the laws relating to licensing trade and other matters related therein This act also prohibits the opening up or operating any trading activity without an authorized trading license. ${ }^{22}$

The Companies Act 2012 provides for the laws relating to formation of companies and winding up of companies and other associations and to make provisions for other related and connected matters.

\section{Protection of the health and safety of the nation's farms.}

The legal sector protects the agricultural sector from adverse forces. This includes systems designed to protect animals and plants from pests, diseases and exotic species. Another protective legislation is the promulgation of standards for the development and sale of important agricultural inputs such as seeds, feeds, fertilizers and agriculture. The Plant Protection Act Cap 31, prohibits the introduction and spread of destructive diseases.

Standardization in Production: Standardization is an incentive because at the end of the production value chain the goods will pass the public health and safety tests. The Plant Protection and Health Act, consolidates laws relating to the protection of plants against destructive disease, pests and weeds to prevent the introduction and spread of harmful organism that may affect Uganda's Agriculture. This also guarantees the production of goods that meet the public health standards.

\section{Capital Incentives;}

The government of Uganda has in years established several initiatives to avail capital to farmers in terms of agriculture and animal husbandry startup capital. Some of these schemes are not just presidential initiatives but they are created by law. Some of these schemes in- 
clude the "Entandikwa Credit or Seed money Scheme of the 1990s", the "Bona Bagawale Scheme of 2007" and now the "Operation Wealth Creation" initiative launched in July 2013 by the President of Uganda to bring about prosperity for all. These initiatives have guaranteed access to seedlings, farm products, starter capital and guaranteed the provision of technical advice needed by famers in production process.

\section{Tax Reductions and exemptions on Agriculture inputs:}

The VAT Act and the Income Tax Act give powers to the Commissioner General, to offer tax exemptions in certain instances, when it comes to agricultural production. Regarding the Import of plant and machinery, the Import duty is NIL by tariff. VAT is deferred and withholding tax is $6 \%$ as long as the cost of plant and machinery is above US $\$ 22,500$. Traders are required to apply to the Commissioner Trade Customs for the facility in writing and must be register for VAT. This tax guarantees cover plant machinery of HS code 8432 like planters, harvesters, seeders, weeders, hoes, irrigators, cultivators, ploughs, fertilizers, etc used in agriculture. Dairy industry (refrigerated trucks, insulated tankers and heat insulated milk tanks). ${ }^{23}$

Tax emptions have been levied on all agricultural inputs. Additionally, all farmers engaged in agro processing can apply for tax exemptions and also farmers engaged in Horticulture or aquaculture or Floriculture, can also apply for tax emptions on inputs imported.

The above are some of the legal incentives to the Agricultural sector in Uganda and the EAC countries can draw lessons from such.

\section{E. BIBLIOGRAPHY.}

\section{Publications.}

EAC Statistics for 2019, see also the EAC Trade Report $2018 \mathrm{http} / /$ repository.eac.int/bitstream/handle/ 11671/2057/EAC\%20Trade\%20Report\%202018.pdf?sequence=1\&isAllowed=y accessed on $2^{\text {nd }}$ November 2020.

Uganda National Household Survey (UNHS) 2016/17.

The East African Community, 'EAC at a glance, 2020.' Accessed on www.eac.int accessed on $1^{\text {st }}$ November, 2020.

The Ministry of Agriculture, Animal Husbandry and Fisheries, 'Agricultural Sector Potential in Uganda, 2020. www. Agriculture.go.ug accessed on $30^{\text {th }}$ October, 2020. (CAADP) is Africa's policy framework for agricultural transformation, wealth creation, food security and nutrition, economic growth and prosperity for all.

23 Uganda Investiment Authority, 'Tax Incentives for Agricultural Sector in Uganda;' https://www.ug andainvest.go.ug/wp-content/uploads/2016/03/Tax-incentives-in-the-Agriculture-sector.pdf accessed on 3rd November, 2020. 
Precision Agriculture, 'Benefits of Documenting Data in Farm Management,' https://precisionagricultu .re/benefits-of-documenting-data-in-farm-management/ accessed on $2^{\text {nd }}$ November, 2020.

Uganda Investment Authority, 'Tax Incentives for Agricultural Sector in Uganda;' https://www.uganda invest.go.ug/wp-content/uploads/2016/03/Tax-incentives-in-the-Agriculture-sector.pdf accessed on 3rd November, 2020.

\section{Thesis/Research Papers;}

Aziz Kitaka, Agriculture and the Law in Uganda (with cases and other relevant materials) in Academia, https://www.academia.edu/39963734/Agriculture_and_the_Law_in_Uganda_With_cases_an d_other_relevant_materials_accessed on 6th November, 2020.

Emmanuel Kazimbazi, 'Legal and Regulatory Framework for the Agriculture Sector in Uganda.' in International Yearbook of Soil Law and Policy book series (IYSLP). https://link.springer.com/chap ter/10.1007/978-3-030-36004-7_4 accessed on 2nd November 2020.

\section{Legislations;}

1. Domestic Legislation.

The 1995 Constitution of Uganda.

The Land Act Cap. 227.

The Sugar Control Act Cap. 34

The Sugar Cess Act Cap 343

The Investment Code Act, 2019.

And other laws referred in the text.

\section{International/Regional Legislation}

The Treaty Establishing the East African Community.

The East African Community Common Market Protocol. 